\title{
THE IMPORTANCE AND IMPACT OF DETERMINANTS INFLUENCING BUSINESS INTELLIGENCE SYSTEMS EMBEDDEDNESS
}

\author{
Tanja Grublješič, Faculty of Economics, University of Ljubljana, Slovenia, tanja.grubljesic@ef.uni-lj.si \\ Pedro Simões Coelho, Universidade Nova de Lisboa, ISEGI, Portugal, Faculty of Economics, University of \\ Ljubljana, Slovenia,psc@isegi.unl.pt \\ Jurij Jaklič, Faculty of Economics, University of Ljubljana, Slovenia, Universidade Nova de Lisboa, ISEGI, \\ Portugal,jurij.jaklic@ef.uni-lj.si
}

\begin{abstract}
This study provides a better understanding of BIS use by extending the most commonly used dimension of measuring usage, that is the intensity of use, to the extent of use and embeddedness of BIS. We further introduce focus on the customer as a predictor in addition to the combined impact of the established acceptance and use determinants, which has not previously been studied. The conceptual BIS embeddedness model was tested and analyzed by structural equation modeling based on survey data. The results show that the determinants play distinct roles in predicting different dimensions of BIS use. In BIS context use, the traditional determinants of effort and performance perceptions play no significant role in predicting BIS use, but organizational factors, such as social influence, facilitating conditions and a focus on the customer, boost the expansion of BIS use and a qualitative leap in use - embedding BIS into the routines of workers.
\end{abstract}

Keywords: Business intelligence systems, BIS use, BIS acceptance, BIS embeddedness

\section{INTRODUCTION}

User acceptance is crucial for any information system success, but in the Business Intelligence Systems (BIS) context there is a particularly pronounced difference between on one hand using or accepting the system and, on the other, the long-term routinization [2] of using the information provided by BIS within the management of organization and business processes [27]. Therefore, the motivation for this study is to understand the contextspecific determinants influencing acceptance of BIS via the various dimensions of use from initial acceptance through the expansion and intensity of use to embeddedness. Petter and McLean [25] point to the need to analyse the link between the dimensions of performance for specific IS separately. Also Venkatesh and Bala [37] say that developing context-specific acceptance and use determinants has "immense value in theorizing richly about the specific IT artefact in question and identifying determinants that are specific to the type of technology being used".

Previous research on information systems (IS) acceptance has mainly focused on general IS and thereby only considered the narrower aspect of use, merely the frequency of use and not how IS are used [8], [35], [37]. While the use of operational IS is mostly seen as a tool to execute operational business processes, for BIS, there is a larger distinction between the use of the system and users' activities based on the information provided by BIS, i.e. when the use of BIS becomes an integral part of the business value generation process. Thus, when studying effective BIS acceptance and use we broaden the notion of use, by considering different dimensions of use, from mere frequency and intensity of use [8]to the extent of use and embeddedness of BIS. Seah, Hsieh and Weng [29] present evidence that certain specific factors determine and encourage the implementation and adoption of BIS. With this study, we thus extend earlier work on IS acceptance by providing evidence of the specific determinants influencing various dimensions of BIS use. The main goal is to understand the mechanisms for increasing the utilization and business value of BIS in organizations by enhancing the possibility of BIS becoming deeply embedded within the business to create "BI-driven decision-making routines and BI-enabled organizational processes that take managerial decision making to new levels of understanding and foresight" [30].

Although the conceptualization of the BIS Embeddedness model is based on the Technology Acceptance Model (TAM) [7], the Unified Theory of Acceptance and Use of Technology (UTAUT) [36] and the Technology Acceptance Model 3 (TAM3) [37] we have extended these theories with the inclusion of a Focus on the customer 
determinant that has emerged as vital in the context of BIS acceptance and use [16]. These theories are further extended with the measurement of the different dimensions of BIS use, namely intensity, extent and embeddedness.

The structure of the paper is as follows. In the next section BIS embeddedness specifics are elaborated. The research model is then conceptualized and hypotheses are developed. Further on, the research design, methodology and results of the estimation are given. This is followed by a discussion of the results including the implications for research and practice and a conclusion.

\section{BIS EMBEDDEDNESS SPECIFICS}

To study the influence of determinants impacting BIS acceptance along with various dimensions of their use, that is in both pre- and post-technology adoption phases, it is important to understand the specific characteristics of BIS compared to operational systems [27], [16]. The use of BIS is voluntary in most cases and for operational IS the use is mostly mandatory or necessary for carrying out the business processes. Venkatesh and Davis [35], Venkatesh et al. [36] and Venkatesh and Bala [37] have already identified the importance of the voluntariness of use when studying IS usage behavior. Further, the structure of users is different, where BIS users are generally more educated workers and mostly managers and operational IS users are all organizational and educational levels' workers. The data in BIS are more aggregated and integrated at the level of entire organization and there is more sharing of information, which relates to the need for an improved information culture. The information needs in BIS are much less structured and the methods for identifying them are often ad-hoc, research-oriented and innovative in nature. Operational IS as well as older decision-support systems and executive IS are more oriented to the software solution and BIS more to the necessary data, centered around data warehousing and providing the analytical tools required to integrate and analyze organizational data. With operational IS, the focus on information quality problems entails traditional problems of data quality such as accuracy and completeness, whereas the focus of BIS is more on the relevance of the information that is provided [27]. In general, compared to operational IS, the benefits of BIS are much more indirect and long-term which may negatively affect their perceived usefulness and, thus, their acceptance and use.

As the object of use investigated in acceptance models has mostly been general IS and in many cases at least implicitly operational IS, where using an IS is seamlessly integrated with execution of the business process, the use of IS has primarily been measured by the frequency, intensity and duration of use (e.g. [8]). But when it comes to BIS use these measures are insufficient since, for BIS to be effectively used, mere intensity does not reflect the desired and promised outcomes from these systems as it is essential for them to be deeply embedded within the business [30]. The frequency of use does not capture the difference between successful or meaningful use and unsuccessful time spent using the system [9]. When studying BIS acceptance and use we therefore employ BurtonJones and Straub's [4] dimensions of system usage measured as the use of information from BIS, which are the frequency or intensity of use, the extent of use and the nature of use. Embeddedness can be understood in the BIS context as the desired or preferred nature of use. Burton-Jones and Straub [4] also identified that different dimensions of use have diverse statistically significant impacts on performance, therefore it is reasonable to explore the drivers of each dimension separately.

The intensity of use [8], [35], [36], [37], [38] is the dimension most commonly employed in the literature to measure the use of IS. This dimension of use has most often been conceptualized and operationalized as the frequency or duration, based on users' self-assessment of the time spent using a system [7], [35], [37] or the duration of their usage via system logs [32], [36]. However, these conceptualizations are limited because they do not capture the difference between effective and meaningful use and the problems users report when using the system leads to lost work time [9].

The extent of BIS use should capture the "extent to which the user employs the system to carry out the task" [4]. In the post-adoption context, more use is not always considered desirable. In this context Po-An Hsieh and Wang [26] introduce the term "extended use" that refers to using more of the complex system's features to support individual's task performance, that can potentially lead to better results and realize the promised return on investments [19]. Deng and Chi [9] argue that BI application context offers an ideal opportunity to examine a variety of post-adoptive system uses. 
Embeddedness represents a qualitative leap in use and can be understood as the level "to which the use of BIS is an integral part of organizational activity" [14]. Embeddedness has been conceptualized and named in several different ways in the literature. From the technology diffusion perspective, in the post-adoption phase of stage model of IT implementation developed by Saga and Zmud [28], use should evolve from initial acceptance through the routinization phase to infusion, which occurs when BIS becomes more deeply embedded within the organization's work system. Notwithstanding this, we still commonly encounter the connection view of BIS in which BIS is understood and used only as a tool by people (managers) to help them in their work [12]. In the context of BIS, fusion involves deeply embedding BIS within the business to create "BI-driven decision-making routines and BIenabled organizational processes that take managerial decision making to new levels of understanding and foresight" [30] within the business process management framework. Bhattacherjee [2] has studied IS continuance as the post-acceptance stage based on expectation-confirmation theory and found support for embedded use, which is a stage when use "transcends conscious behavior and becomes part of normal routine activity", also considering and explaining why some users discontinue IS use after initially accepting it. That is why Burton-Jones and Straub [4] conceptualize the dimension of deep structure usage as exploitive system usage, which is the "extent to which users exploit features of the system to perform the tasks". Jasperson et al. [19] elaborate that much post-adoptive behavior or continuing IT use is likely to reflect a "habitualization of action, where the decision to use the IT application feature occurs more or less automatically via a subconscious response to a work situation" and Ortiz de Guinea and Markus [24] support this habitual use. Ortiz de Guinea and Markus [24] argue that "automatic (i.e. habitual) IT use behavior may be much more extensive than the simple repetition of well-learned behavioral sequences", which in turn supports use embedded into the routines of users.

\section{CONCEPTUALIZATION OF THE RESEARCH MODEL}

The theoretical model in this study combines aspect of the TAM [7], UTAUT [36] and TAM3 [37] in a complimentary manner reinforced by findings from the case studies analysis of BIS acceptance and use [16]. The motives underlying the acceptance and effective use of BIS indeed introduce additional significant constructs (like a focus on the customer) that cannot be satisfactorily dealt with or explained solely by existing theoretical frameworks or acceptance models individually. Based on this, we propose an integrated theoretical framework created from a synthesis of the relevant constructs of existing theories and extended with additional constructs derived from best practices in the context specific environment [16].

The TAM proposed by Davis [7]provides a seminal framework for this study. It proposes that two distinctive behavioral beliefs - perceived usefulness and perceived ease of use - provide the individual's behavioral intention to use a technology, and the actual use is determined by behavioral intention [7]. However, the TAM focuses on individual beliefs about a technology that form behavior (e.g. the use of a system) and seems to disregard some organizational and external factors that could also influence user perceptions of a certain technology. Therefore an integrative view of antecedents of acceptance is needed as well as context-specific variables. On individual acceptance and consequently on the success of IS increasingly influence organizational factors [42] and some environmental characteristics (e.g. competitiveness of the environment) [33]. These have been found as vital for the embeddedness of BIS within an organization's work system in Grublješič and Jaklič [16] case study. Further, social influence as well as result demonstrability are being increasingly recognized as having an influence on an individual's cognitive process to perform a behavior [36], [37].

The UTAUT model [36] incorporates in addition to TAM's constructs perceived usefulness and perceived ease of use (measuring them as expectations) the independent impact of social influence and facilitating conditions on behavior. In the BIS context social influence plays especially important role for the widespread use and embedding BIS into business [16]. Thus this determinant is included in our model, as use is mostly voluntary and benefits of use are more indirect and long-termed as compared to operational IS. If users perceive that the results of use are visible (Venkatesh and Davis, 2000) and bring benefits to their image [22], the use of BIS is expected to become more embedded into their routines [16]. Relatedly, also result demonstrability of using BIS, as having knowledge of the actual results of work activities, presenting the key psychological state underlying work motivation [1], was found to be crucial for BIS acceptance in Grublješič and Jaklič [16] exploratory study. Agarwal and Prasad [1] found significant relationship between result demonstrability and usage intentions. The tangible recognition of benefits, measured by result demonstrability is positively correlated with performance perceptions. Agarwal and Prasad [1] say they "appear to work in tandem", since users are concerned with "rationalizing their decisions both to 
themselves as well as to the others to avoid cognitive dissonance". These two constructs are therefore related but measure different perceptions. Performance perceptions relate to efficient (and immediate) worker performance using the system while result demonstrability to effectiveness of an individual relating to long-termed impact of using the system on organizational performance. Since UTAUT model encompasses vital antecedent determinants important for BIS acceptance, we base our BIS Embeddedness model on UTAUT with integration of result demonstrability from TAM3. UTAUT's "performance expectancy" and "effort expectancy" are operationalized as perceptions, based on TAM's perceived usefulness and perceived ease of use [7]. Effort perceptions therefore encompass the extent of ease associated with BIS use and performance perceptions the extent to which a person believes that using BIS enhances his or her work performance [36], [37]. All of the accounted models postulate behavioral intention to accept IS as the primary direct determinant of behavior, and Taylor and Todd [32] provide support for the predictive power of behavioral intention as an important mediating variable influencing behavior. Based on the joint influence of combined TAM, UTAUT and TAM3 constructs, found important in this context, we pose our first four hypotheses:

H1: Effort perceptions positively influence Behavioral intention to use BIS.

H2: Performance perceptions positively influence Behavioral intention to use BIS.

H3: Social influence positively influences Behavioral intention to use BIS.

H4: Result demonstrability positively influences Behavioral intention to use BIS.

By conceptualizing three different dimensions of BIS usage, throughout the reasoning explained in the previous chapter, we try to capture all relevant aspects of effective use of BIS. In order to know how to improve each dimension of use, we need to understand the mechanisms that drive each aspect of use. Research suggests that the amount of time spent on an activity (intensity and duration of use) is best predicted by internal motivation (behavioral intention). On the other hand the work activities that make up an employee's job and how system use is embedded in work routines (extent of use and embeddedness) are instead determined by external needs that relate to the work environment [38]. Through this reasoning, we thus hypothesize that the antecedents of use behavior will exert varying impacts on different dimensions of use.

One of the determinants directly influencing usage behavior is facilitating conditions [36] which are defined as "the degree to which an individual believes that an organizational and technical infrastructure exists to support use of the system". In the UTAUT [36] the determinant of facilitating conditions is hypothesized to directly influence system use based on the idea that in an organizational environment, many aspects of facilitating conditions, such as training and support provided, will be available within an organization freely and fairly invariant across users [39]. It has been demonstrated that when both performance expectancy and effort expectancy constructs are present, facilitating conditions become non-significant in predicting behavioral intention [36]. Venkatesh [34] also found support for full mediation of the influence of facilitating conditions on intention by effort expectancy. Facilitating conditions thus have a direct influence on usage beyond that which is explained by behavioral intention and are modeled as a direct antecedent of usage. In the BIS context, there is a particular emphasis on the presence of a BIS project leader and having a pronounced sponsor of BIS, which helps a great deal in ensuring the BIS becomes embedded throughout the organization and in building a culture of regular, deep structural BIS usage [16]. After integrating these arguments, we put forward the next hypotheses:

H5a: Facilitating conditions positively influence the Intensity of BIS use.

H5b: Facilitating conditions positively influence the Extent of BIS use.

H5c: Facilitating conditions positively influence the Embeddedness of BIS.

H5d: Facilitating conditions have different positive impacts on the three dimensions of the use of BIS.

Behavioral intention is an important causal predictor of behavior that mediates the influence of various beliefs and external factors (e.g. effort perceptions, performance perceptions, result demonstrability and social influence) on behavior [8]. The formation of an intention to carry out behavior is thought to be a necessary precursor to behavior and the inclusion of intention has been found to increase the predictive power of models relative to models which do not include intention [32]. But individuals' beliefs and consequently their behavioral intention can change when they are faced with new information and due to various internal and external stimuli they may become less predictive of behavior over time [38]. Greater usage experience may imply "opportunities to strengthen the link between cues and behavior, which then facilitates habitualization" [39]. We should therefore expect that behavioral intention should 
have varying impacts on different dimensions and complexities of BIS use. Following this rationale, we hypothesize:

H6a: Behavioral Intention positively influences the Intensity of BIS use.

H6b: Behavioral Intention positively influences the Extent of BIS use.

H6c: Behavioral Intention positively influences the Embeddedness of BIS.

H6d: Behavioral Intention has different positive impacts on the three dimensions of the use of BIS.

An organizational focus on the customer emerged as a salient determinant influencing BIS acceptance in the casestudy analysis of Grublješič and Jaklič [16] and was thus included in our BIS embeddedness model as having a direct impact on use behavior. This determinant has not been included in previous IT acceptance models and provides valuable insights concerning the context specific issues. A focus on the customer relates to the competitiveness of the environment in which organizations operate and hence market-oriented organizations are more dependent on innovative and competitive information [20]. As BIS provide innovative information, they are a prerequisite for many organizations to compete in the marketplace [41], particularly when they operate in highly competitive environments [27]. A customer orientation should have a favorable impact on business performance and enhance customer satisfaction as well as organizational productivity [10]. Prior studies suggest that IT implementation plays the role of a complementary asset for communication with customers [13]. Accordingly, the extent of use dimension also measures the use of BIS to provide a more differentiated and customized service to customers [11]. Integrating these arguments we should expect that employees in organizations that focus on customers use BIS more and that particularly BIS should be more embedded into their routines:

H7a: A Focus on the customer positively influences the Intensity of BIS use.

H7b: A Focus on the customer positively influences the Extent of BIS use.

H7c: A Focus on the customer positively influences the Embeddedness of BIS.

H7d: A Focus on the customer has different positive impacts on the three dimensions of the use of BIS.

\section{RESEARCH DESIGN AND METHODOLOGY}

The questionnaire was developed by building on previous theoretical basis to assure content validity. To ensure face validity, pre-testing was conducted, using a focus group involving selected university staff and IS academics from the field, who were not included in the subsequent research. Minor changes were made based on their suggestions, mostly involving the adaptation of the questionnaire items to the specific context of BIS use, i.e. integrating voluntariness of use in the indicators and unifying operationalization of all indicators to measure perceptions. We used a structured questionnaire with seven-point Likert scales.

The measurement items were developed based on literature review and supported by expert opinions. To measure the effort perceptions construct, we used previously researched and validated items (four items) provided by Venkatesh et al. [36], operationalizing them to measure perceptions, based on TAM's perceived ease of use [7]. We used six items to measure performance perceptions, which were taken from from Venkatesh et al. [36], Davis et al. [8], Venkatesh and Bala [37], and Compeau, Higgins and Huff [5] in order to fully capture and reflect the context specific performance perceptions. Four items for measuring social influence were adapted from Venkatesh et al. [36]. Result demonstrability was measured by four validated items adopted from Venkatesh and Bala [37] based on Moore and Benbasat [22]. The facilitating conditions scale was developed by combining four items from Venkatesh et al. [36], one item from Goodhue [15] and another item was established based on Shanks et al. [30] renewal capability dimension, which measures if BIS capabilities are continuously renewed to provide valuable insights. A Focus on the customer construct was measured using six items with highest factor loadings from Liu et al. [21] customer orientation construct. Behavioral intention three-item scale was drawn from Wixom and Todd [40], operationalized to measure creation of beliefs dependent on volitional state. Use behavior was measured as a reflective composite index of three dimensions, capturing intensity, extent and embeddedness of BIS use, following Burton-Jones and Straub's [4] classification. These three aspects of BIS use have been conceptualized as three different constructs, since we expect that there will be diverse impacts on these three aspects of use. BIS embeddedness items were developed based on Shanks et al. [30] dimensions of BIS embeddedness in the business. The three intensity of use items were adapted from Wixom and Todd [40], capturing increasing intensity of BIS use. Extent of BIS use was measured by adapting Doll and Torkzadeh [11]. Each concept was measured with three item 
scales having highest factor loadings [11]. Detailed questionnaire with the indicators of the measurement model can be obtained from the authors upon request. Our proposed measurement model involved 60 manifest or observable variables loading on to 10 latent constructs (1) Effort perceptions; (2) Performance perceptions; (3) Social influence; (4) Result demonstrability; (5) Facilitating conditions; (6) A Focus on the customer; (7) Behavioral intention; and three dimensions of BIS use, namely (8) Intensity of BIS use; (9) Extent of BIS use; and (10) BIS embeddedness.

The data were collected through a survey of 2173 medium- and large-sized business organizations in an EU country, namely Slovenia. Organizations were selected from an official database published by a National Agency for Public Legal Records. Questionnaires were addressed to a wide range of employees, that is, all users of BIS (top management, heads of departments and divisions, IS managers, etc.). The questionnaires were sent to the contact persons available in the database, with a request to distribute the questionnaires to relevant users of BIS. A total of 195 competed surveys were collected after a follow up survey. The final response rate was $9.3 \%$.

\section{RESULTS}

To conduct the data analysis, a form of structural modelling, namely partial least squares (PLS) path modelling using Smart PLS was chosen. These techniques are widely selected in the information systems field, since they are suitable for predictive applications and theory-building because they examine the significance of the relationships between research constructs and the predictive power of the dependent variable [5]. Two reasons motivated the choice of PLS path modeling. Firstly, PLS path models can be very complex, i.e. they consist of many latent and manifest variables, and the number of these may be high in relation to the number of observations [17] as in our case. The second is its suitability for a relatively small sample size as is the case in our research [17]. The guideline for such a sample size when using PLS modelling is that the sample should be equal to or larger than ten times the largest number of paths directed at a particular construct in the model [5]. The minimum acceptable sample size is thus forty, derived because the largest number of structural paths directed at the construct behavioral intention is four.

We have first examined the reliability and validity measures for our reflective measurement model. Once the manifest variables that did not load satisfactory had been removed, the model was rerun. In the final model, all Cronbach's alphas by far exceeded the 0.7 threshold [23]. Without exception, the latent variables composite reliabilities were higher than 8.0 and in most cases even higher than 0.9 (which are the thresholds for more advanced stages of research) showing the high internal consistency of indicators measuring each construct and thus confirming construct reliability. The Average Variance Extracted (AVE) was generally around 0.6 or higher (only AVE for facilitating conditions was 0.59 ), exceeding the threshold of 0.5 for all constructs, demonstrating the convergent validity of the constructs. The reliability and convergent validity of the final measurement model were also confirmed by computing standardized loadings for the indicators and Bootstrap t-statistics for their significance. All standardized loadings of the indicators in the final model exceeded (or were marginal to) the 0.7 threshold and they were found without exception to be significant at the 0.001 significance level, thus confirming the high indicator reliability and convergent validity.

The assessment of the indicator loadings on their corresponding constructs was the first procedure for testing the discriminant validity. The results indicated that manifest variable correlations with their theoretically assigned latent variables are an order of magnitude larger than other loadings to other constructs. Therefore, all the item loadings met the criteria. Further, we have compared the square root of AVE for each construct with the correlations with all other constructs in the model. The square roots of AVE were significantly higher (and also substantially larger than the threshold) than the correlations between the constructs, thus confirming that they are sufficiently discriminable.

As shown in Figure 1 the influence of effort perceptions, performance perceptions, social influence and result demonstrability explain about $28.7 \%$ of the variance in behavioral intention. Looking at the explained variability of the intensity of BIS use, it can be seen that $51.2 \%$ of the variance in intensity of use is explained by the influence of behavioral intention and facilitating conditions (as a focus on the customer was found to play no significant role). Further on, the influence of behavioral intention and facilitating conditions explain $32.6 \%$ of the variance in the extent of BIS use (as again a focus on the customer influence proves to be statistically insignificant). Finally, it can be seen that $36.7 \%$ of the variance in embeddedness of BIS is explained by the influence of behavioral intention, facilitating conditions and a focus on the customer as well. Since the exogenous variables explain moderate to high 
proportions of the variance of the endogenous variables, we may conclude that the model holds sufficient explanatory power and is capable of explaining the constructed endogenous latent variables.

The impact of the effort perceptions on behavioral intention was found to be non-significant, thus hypothesis $\mathrm{H} 1$ is rejected. Hypothesis $\mathrm{H} 2$ can be conditionally supported (at 10\% significance level), but the effect of the performance perceptions on behavioral intention shows a weak magnitude ( $\hat{\beta}=0.144)$. The path coefficients associated with $\mathrm{H} 3$ and $\mathrm{H} 4$ are statistically significant at the $5 \%$ and $1 \%$ significance level, respectively, thus supporting these two hypotheses. As indicated by the path loadings, social influence $(H 3: \hat{\beta}=0.228)$ and result demonstrability (H4: $\hat{\beta}=0.242$ ) have significant direct and positive influence on behavioral intention.

Hypotheses $\mathrm{H} 5 \mathrm{a}, \mathrm{H} 5 \mathrm{~b}$ and $\mathrm{H} 5 \mathrm{c}$ are supported, showing that facilitating conditions have statistically significant (at the $0.1 \%$ significance level) direct and positive influences on all three dimensions of use. As indicated by the path loadings, facilitating conditions positively influence intensity of use $(\hat{\beta}=0.456)$, extent of use $(\hat{\beta}=0.353)$ and embeddedness of BIS ( $\hat{\beta}=0.355$ ). The t-statistics for the difference between impacts of facilitating conditions on intensity of BIS use and facilitating conditions on extent of BIS use is 1.96 with $\mathrm{p}=0.05$, hence confirming that the two hypothesized impacts are indeed different. The second pair wised comparison (facilitating conditions impact on intensity of BIS use and facilitating conditions impact on embeddedness of BIS) proved to be conditionally significant (at $\mathrm{p}=0.08$ ) with $\mathrm{t}$-value of 1.71 , and the last comparison (facilitating conditions impact on extent of BIS use and facilitating conditions impact on embeddedness of BIS) was found to be statistically non-significant (H5d).

Further on the results show full support for hypotheses H6a, H6b and H6c, where behavioral intention has statistically significant (at the $0.1 \%$ significance level for intensity and extent of BIS use, and at $1 \%$ for the embeddedness of BIS) direct and positive influences on all three dimensions of use. The path loadings indicate that behavioral intention positively influences intensity of BIS use ( $\hat{\beta}=0.378)$, extent of BIS use $(\hat{\beta}=0.269)$, and embeddedness of BIS $(\hat{\beta}=0.243)$. The t-statistics (H6d) for the difference of the first pairwise comparison (behavioral intention impact on intensity of BIS use and behavioral intention impact on extent on BIS use) is 1.84 and is conditionally supported (at $\mathrm{p}=0.07$ ). The difference between the second comparison (behavioral intention impact on intensity of BIS use and behavioral intention impact on embeddedness of BIS) proved to be statistically significant (t-value $=2.4$ and $\mathrm{p}=0.02$ ), thus confirming that the two hypothesized impacts are indeed different. The last comparison showed a statistically non-significant difference; hence the impact of behavioral intention on extent of BIS use and the impact of behavioral intention on embeddedness of BIS are not significantly different. 


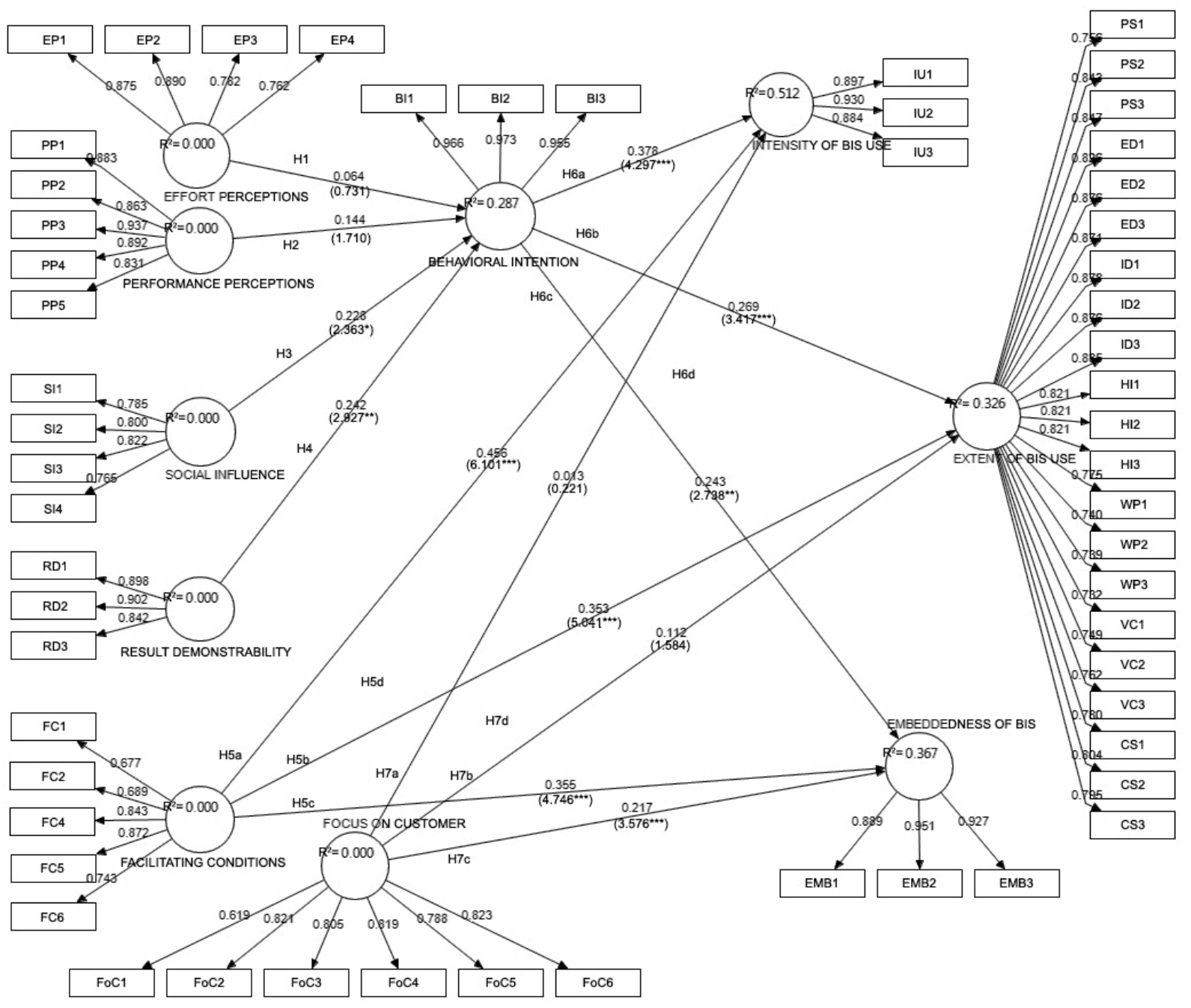

Figure 1. The final measurement model

Notes: (ns) non-significant; * significant at 0.05 level (two-tailed test); ${ }^{* *}$ significant at 0.01 level (two-tailed test); $* * *$ significant at 0.001 level (two-tailed test)

The hypotheses associated with the impact of a focus on the customer on different dimensions of use were not all supported. The impact of a focus on the customer on intensity of use $(\hat{\beta}=0.013)$ and on extent of use $(\hat{\beta}=0.112)$ was found to not be statistically significant; hence the hypotheses $\mathrm{H} 7 \mathrm{a}$ and $\mathrm{H} 7 \mathrm{~b}$ are rejected. But on the other hand, the path loading indicates, that a focus on the customer has direct and positive statistically significant $(\hat{\beta}=0.217$, $\mathrm{p}<0.001)$ influence on embeddedness of BIS. The t-statistics for the difference between pair wised comparisons (H7d) showed that the first pair wised comparison (a focus on the customer impact on intensity of BIS use and a focus on the customer impact on extent on BIS use) was conditionally supported (with $t$-value $=1.79$ and $p=0.07$ ). The difference between the impact of a focus on the customer on intensity of BIS use and the impact of a focus on the customer on embeddedness of BIS proved to be statistically significant ( $\mathrm{t}$-value $=3.10$ and $\mathrm{p}=0.002$ ), hence confirming that the two hypothesized impacts are indeed different. The last pair wised comparison showed no statistically significant difference between the impacts of a focus on the customer on the extent and embeddedness of BIS. 


\section{DISCUSSION AND CONCLUSIONS}

Our findings from the model analysis (particularly assessments of discriminant validity) provide proof supporting the conceptualizing of the three different dimensions of BIS use and further bring novel insights about what are the antecedents that influence on them and how to analyze them in an important specific context of BIS use.

The results of our study provide support for some of the findings from existing verified models of IT acceptance, but also contrast them with important established conceptions. In the BIS context, it is evident that effort perceptions and performance perceptions have no significant impact on behavioral intention. So both major determinants from the TAM model [7] play no considerable role in acceptance and use of BIS, which can be reasoned with the specifics of BIS use. Users of BIS are therefore willing to invest more effort to use BIS, even in early stages of this new behavior (in contrast to findings from Venkatesh et al. [36]), since when using BIS, the focus in not so much on improving the effectiveness, such as speed of work performance, but mostly to make better decisions and show better results [27]. Therefore, in this context carrying out processes quickly is not as great a priority as ensuring that managers make better decisions with the use of and by embedding BIS into their routines [30].

In the BIS context social influence and result demonstrability seem to impact on behavioral intention to use BIS. Since use of BIS is primarily voluntary and benefits of use are more indirect and long termed as compared with operational IS, individual's intentions to use BIS are more influenced by their beliefs about how others will view them as a result of using BIS [36], [16]. Therefore if users perceive benefits particularly on their image, corresponding with potential social status gains [36] and that the results of use are visible, the use of BIS will become more embedded into their routines [16]. This is consistent with the findings of Venkatesh and Davis [35] who argue that in voluntary settings the mechanism of "internalization" comes to fore, which refers to the process "by which, when one perceives that an important referent thinks one should use the system, one incorporates the referent's belief into one's own belief structure". Furthermore internalization explains why direct impact of performance perceptions on intention appears not to play a significant role, but is rather incorporated in social influence and result demonstrability. As Venkatesh and Davis [35] say "if a superior or co-worker suggests that a particular system might be useful, a person may come to believe that it actually is useful, and in turn form an intention to use it". The perceived tangible and demonstrable recognition of benefits [1], captured by result demonstrability, seems to impact on users' intentions to use BIS. Therefore, intention to use BIS is thus not driven by direct performance perceptions, i.e. perceptions of faster and easier access to information, but by perceptions that they can contribute and improve business performance, based on the information provided by BIS, which presents the added value of BIS [27].

Traditional models of acceptance have provided sound evidence for the predictive power of behavioral intention as a direct determinant of target behavior, which is use of the system [8], [32], [36], [37], [38], but have measured use only as frequency, intensity or duration of use. Our study confirms the extensively researched impact of behavioral intention on intensity of use, and this influence is also proven to be very strong. Furthermore, it is evident that behavioral intention explains also the variation in the extent and embeddedness of BIS use, but this direct impact is somewhat lower than on the intensity of use, therefore it is necessary to search for additional determinants to explain these two dimensions of use. The model provides support for the strong impact of facilitating conditions on intensity of use, and shows the predictive ability of facilitating conditions in removing barriers to sustained usage. Therefore, users' beliefs about the existence of organizational and technical infrastructure to support BIS use [36] has the strongest impact on intensity of use, and thereby represents a prerequisite for the expansion of use and the embeddedness of BIS into the routines of workers.

Literature has already established the importance of IT in creating and enhancing communication and value proposition for customers [31], [13]. Market oriented (or customer oriented) organizations [10] are more dependent on innovative and competitive information [20]. All these issues speak in favor of using BIS to create competitive advantage [41], as BIS provide innovative and competitive information, strategically oriented information processing and analysis [17], which can increase customer satisfaction and organizational productivity [10] and ultimately improve organizational performance [27]. The results show that an organizational focus on the customer impacts on embeddedness of BIS into the organization's work system. There was no statistically significant impact of a focus on the customer on intensity of BIS use nor on the extent of use, but it influences on integration of BIS use with business processes, embeddedness of BIS into the decision-making routines and alignment of insights from 


\section{Issues in Information Systems \\ Volume 15, Issue I, pp. 106-117, 2014}

BIS with business strategy [30]. These results are in line with the findings of Birgelen, Ruyer and Wetzels [3] that "commitment toward customer satisfaction has a positive impact on the acceptance and use of customer satisfaction information for the purpose of customer-oriented priority setting". Taking into the consideration the characteristics of BIS, it can be concluded that, if organizations are focused on customers' needs the management of processes, data analysis and fact-based decision making using BIS has to be routinized and embedded into the routines of decisionmakers for the purpose of satisfying customers.

Our findings provide proof supporting the conceptualizing of the three different dimensions of BIS use. We particularly introduce a dimension of embeddedness of BIS, which has not been included and studied in acceptance models previously. This provides a significant addition for understanding deep structural use of BIS that contributes to the success of BIS. Embeddedness of BIS into the routines of workers should lead to improvements of business processes, improve firm performance and create competitive advantage [30]. The rich measurement of different types of usage is a response to the observation of Jasperson et al. [19] who encourage researchers to move beyond simplistic views of use (measured only by frequency) in order to "expose the sufficiently rich depictions of use history" and "understand the path-dependent episodes of use leading to routinized or habitual use of an IT application".

In general, findings thus provide novel insights regarding the importance of established predictors of use behavior in BIS use context, emphasizing the prominence of organizational factors such as social influence, result demonstrability, management support and governance mechanisms for BIS renewal aligned with business strategy that should be constantly evolving for continued and effective BIS use. These can only be developed in the long term or constantly and can be classified as trans-implemental measures. Overall, the findings enrich our understanding of the phenomena of post-adoption BIS use behavior.

\section{REFERENCES}

[1] Agarwal, R. and Prasad, J. (1997). The role of innovation characteristics and perceived voluntariness in the acceptance of information technologies, Decision Sciences, 28 (3), 557-582.

[2] Bhattacherjee, A. (2001). Understanding Information Systems Continuance: An Expectation-Confirmation Model, MIS Quarterly, 25 (3), 351-370.

[3] Birgelen, M., Ruyter, K. and Wetzels, M. (2003). The impact of attitude strength on customer-oriented priority setting by decision makers: An empirical investigation, Journal of Economic Psychology, 24 (6), 763-783.

[4] Burton-Jones, A. and Straub, D. W. (2006). Reconceptualizing System Usage: An Approach and Empirical Test, Information Systems Research, 17 (3), 228-246.

[5] Chin, W. W. (1998). Issues and opinions on structure equation modeling. MIS Quarterly, 22(1), viixvi.

[6] Compeau, D. R., Higgins, C. A., and Huff, S. (1999). Social Cognitive Theory and Individual Reactions to Computing Technology: A Longitudinal Study, MIS Quarterly, 23 (2), 145-158.

[7] Davis, F. D. (1989). Perceived usefulness, perceived ease of use, and user acceptance of information technology. MIS Quarterly, 13 (3), 319-339.

[8] Davis, F. D, Bagozzi, R. P. and Warshaw, P. R. (1989). User Acceptance of Computer Technology: A Comparison of Two Theoretical Models. Management Science, 35 (8), 982-1003.

[9] Deng, X. N. and Chi, L. (2013). Understanding Postadoptive Behaviors in Information Systems Use: A Longitudinal Analysis if System Use Problems in the Business Intelligence Context, Journal of Management Information Systems, 29 (3), 291-325.

[10] Deshpande, R., Farley, J. U., and Webster Jr., F. E. (1993). Corporate culture, customer orientation, and innovativeness in Japanese firms: a quadrad analysis. Journal of Marketing, 57 (1), $23-27$.

[11]Doll, W. J. and Torkzadeh, G. (1998). Developing a multidimensional measure of system-use in an organizational context. Information \& Management, 33 (4), 171-185.

[12]El Sawy, Omar A. (2003). The IS Core IX: The 3 Faces of IS Identity: Connection, Immersion, and Fusion. Communications of the Association for Information Systems, 12 (1), 588-598.

[13]Feng, T., Sun, L., Zhu, C. and Sohal, A. S. (2012). Customer orientation for decreasing time-to-market of new products: IT implementation as a complementary asset, Industrial Marketing Management, 41 (6), 929-939.

[14]Furneaux, B. and Wade, M. (2011). An Exploration of Organizational Level Information Systems Discontinuance Intentions. MIS Quarterly, 35 (3), 573-598. 
[15] Goodhue, D. L. (1998). Development and Measurement Validity of a Task-Technology Fit Instrument for User Evaluation of Information Systems, Decision Sciences, 29 (1), 105-138.

[16] Grublješič, T. and Jaklič, J. (2014). Conceptualization of the business intelligence extended use model, Journal of Computer Information Systems, Forthcoming.

[17] Henseler, J., Ringle, C. M. \& Sinkovics, R. R. (2009). The use of partial least squares path modeling in international marketing. Advances in International Marketing, 20, 227-319.

[18] Isik, O., Jones, M. C, and Sidorova, A. (2013). Business intelligence success: The role of BI capabilities and decision environments, Information \& Management, 50 (1), 13-23.

[19] Jasperson, J., Carter, P. E. and Zmud, R. W. (2005). A Comprehensive Conceptualization of Post-Adoptive Behaviors Associated with Information Technology Enabled Work Systems. MIS Quarterly, 29 (3), 525-557.

[20] Lee, G. and Xia, W. (2006). Organizational size and IT innovation adoption: A meta-analysis. Information \& Management, 43 (8), 975-985.

[21]Liu, S. S., Luo, X. \& Shi, Y-Z. (2002). Integrating customer orientation, corporate entrepreneurship and learning orientation in organizations-in-transition: An empirical study. International Journal of Research in Marketing, 19 (4), 367-382.

[22] Moore, G. C. and Benbasat, I. (1991). Development of an Instrument to Measure the Perceptions of Adoption and Information Technology Innovation. Information Systems Research, 2 (3), 192-222.

[23] Nunnally, J. C. and Bernstein, I. H. (1994). Psychometric theory ( $3^{\text {rd }}$ ed.). New York, NY: McGraw-Hill.

[24] Ortiz de Guinea, A. and Markus, M. L. (2009). Why Break the Habit of a Lifetime? Rethinking the Roles of Intention, Habit, and Emotion in Continuing Information Technology Use, MIS Quarterly, 33 (3), 433-444.

[25] Petter, S. and McLean, E. R. (2009). A meta-analytic assessment of the DeLone and McLean IS success model: An examination of IS success at the individual level. Information \& Management, 46 (3), 159-166.

[26] Po-An Hsieh, J. J. and Wang, W. (2007). Explaining Employees Extended Use of Complex Information Systems, European Journal of Information Systems, 16 (3), 216-227.

[27] Popovič, A., Hackney, R., Coelho, P. S., and Jaklič, J. (2012). Towards business intelligence systems success: Effects of maturity and culture on analytical decision making. Decision Support Systems, 54 (1), 729-739.

[28] Saga, V. L. and Zmud, R. W. (1994). The nature and determinants of IT acceptance, routinization, and infusion. In Levine, L. (Ed.), Diffusion, transfer and implementation of information technology. Pittsburgh, PA: Software Engineering Institute, 67-86.

[29] Seah, M., Hsieh, M. H. and Weng, P-U. (2010). A case analysis of Savecom: The role of indigenous leadership in implementing a business intelligence system. International Journal of Information Management, 30 (4), $368-$ 373.

[30] Shanks, G., Bekmamedova, N., Adam, F., and Daly, M. (2012). Embedding Business Intelligence Systems within Organisations. In A. Respício and F. Burstein (Eds.), Fusing Decision Support Systems into the Fabric of the Context, Vol. 238, 113-124, IOS Press.

[31] Tallon, P. P., Kraemer, K. L., and Gurbaxani, V. (2000). Executives' Perceptions of the Business Value of Information Technology: A Process-Oriented Approach, Journal of Management Information Systems, 16 (4), 145-173.

[32] Taylor, S. and Todd, P. (1995). Assessing IT usage: The role of prior experience. MIS Quarterly, 19 (4), 561570.

[33] Tornatzky, L. and Fleischer, M. (1990). The process of technology innovation. Lexington Book, Lexington, Massachusetts.

[34] Venkatesh, V. (2000). Determinants of Perceived Ease of Use. Integrating Control, Intrinsic Motivation, and Emotion into the Technology Acceptance Model. Information Systems Research, 11 (4), 342-365.

[35] Venkatesh, V. and Davis, F. (2000). A Theoretical Extension of the Technology Acceptance Model: Four Longitudinal Field Studies. Management Science, 46 (2), 186-204.

[36] Venkatesh, V., Morris, M. G., Davis, G. B. and Davis, F. D. (2003). User Acceptance of Information Technology: Towards a Unified View. MIS Quarterly, 27 (3), 425-478.

[37] Venkatesh, V. and Bala, H. (2008). Technology Acceptance Model 3 and a Research Agenda on Interventions. Decision Sciences, 39 (2), 273-315.

[38] Venkatesh, V., Brown, S. A., and Maruping, L. M., Bala, H. (2008). Predicting Different Conceptualizations of System Use: The Competing Roles of Behavioral Intention, Facilitating Conditions, and Behavioral Expectation. MIS Quarterly, 32 (3), 483-502. 
[39] Venkatesh, V., Thong, J. Y. L., and Xu, X. (2012). Consumer Acceptance and Use of Information Technology: Extending the Unified Theory of Acceptance and Use of Technology, MIS Quarterly, 36 (1), 157-178.

[40] Wixom, H. B. and Todd, P.A. (2005). A Theoretical Integration of User Satisfaction and Technology Acceptance. Information Systems Research, 16 (1), 85-102.

[41] Wixom, H. B. and Watson, H. (2010). The BI Based Organization. International Journal of Business Intelligence Research, 1 (1), 13-28.

[42] Yeoh, W. and Koronios, A. (2010). Critical Success Factors for Business Intelligence Systems. Journal of computer Information systems, 50 (3), 23-32. 